\title{
FLASH PYROLYSIS KINETICS OF PINE WOOD
}

\author{
B.M. Wagenaar, W. Prins, W.P.M. van Swaaij
}

University of Twente, P.O. box 217, 7500 AE Enschede, The Netherlands.

\begin{abstract}
The kinetics of sawdust pyrolysis in the temperature range from 300 to $600{ }^{\circ} \mathrm{C}$ has been measured. A thermogravimetric analyser was applied for the temperature range from 300 to $450{ }^{\circ} \mathrm{C}$ while for measurements in the temperature range from 450 to $600{ }^{\circ} \mathrm{C}$, an entrained flow reactor has been used. The kinetic expression that describes the mass loss of sawdust due to pyrolysis is assumed to be of a single first-order in the unconverted wood. The first-order rate constant obtained from measurements in both the thermogravimetric analyser and the entrained flow reactor can be described by an Arrhenius equation with $\mathrm{k}_{0}=1.410^{10} \mathrm{~kg} \cdot \mathrm{kg}^{-1} \cdot \mathrm{s}^{-1}$ and $\mathrm{E}_{\mathrm{a}}=150 \mathrm{KJ} \cdot \mathrm{mol}^{-1}$.
\end{abstract}

\section{INTRODUCTION}

Biomass waste materials can be used as a fuel as such, or after conversion processes like pyrolysis or gasification. A direct application is co-firing in existing combustion systems, meant to reduce the amount of waste material while using the heat of combustion of the feedstock. Because biomass contains less sulphur compared to coal, a reduction in the sulphur oxide production can be achieved in a coal fired furnace. Less limestone is then required to bind the sulphur components by which the amount of waste materials produced in the combustion process will be lower. The co-firing of biomass also reduces the $\mathrm{CO}_{2}$ emission because biomass is an integrated part of the natural carbon cycle.

Any description of the combustion or gasification of biomass starts with a description of the pyrolysis process of a single biomass particle. Pyrolysis of sawdust is extensively studied; a survey of previous work is given in a review by Antal [1]. Biomass particles like wood dust have pores with a diameter of 5 $\mu \mathrm{m}$ and porosity of approximately $50 \%$. A hot isothermal particle will have a uniform production of pyrolysis vapours throughout the particle volume. The 
highest pressure occurs in the centre of the biomass particle; it decreases towards the particle surface. Pyrolysis vapours leave the particle due to diffusion and a pressure gradient built-up inside the particle. For the small and open sawdust particles, pyrolysis vapours can leave the particle instantaneously and the decomposition kinetics itself are determining the rate of the process.

\section{KINETIC MODEL}

In absence of any heat or mass transfer limitation, the decomposition of wood is usually described by a single first-order model for weight loss of the reacting aggregate. Because the rate of reaction must be zero when the wood has been converted completely, the driving force for wood pyrolysis must be equal to the total aggregate weight minus the final char weight:

$$
\frac{\partial \mathrm{W}}{\partial \mathrm{t}}=-\mathrm{k}_{1}\left(\mathrm{~W}-\mathrm{W}_{\mathrm{c}}^{\infty}\right)
$$

The mass conversion of wood follows from the experimentally observed weight change:

$$
\zeta_{\mathrm{p}}=\left(\mathrm{w}_{0}-\mathrm{W}\right) /\left(\mathrm{w}_{0}-\mathrm{w}_{\mathrm{c}}^{\infty}\right)
$$

The assumption of a first-order wood decomposition only holds if the mass of the reacting aggregate keeps the same reactivity throughout the entire pyrolysis process. In other words, the first-order rate constant $\mathrm{k}_{1}$ should be independent of the changing chemical structure of the reacting aggregate at any instant in the pyrolysis process. The reaction path model, proposed by Shafizadeh et al. [2], suggests that all chemical decomposition reactions are of first order. It can be represented schematically as:

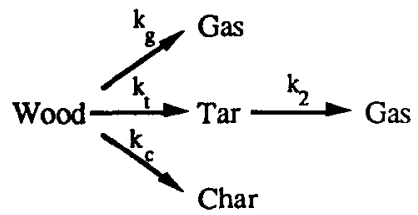

$$
\text { with } \mathrm{k}_{1}=\mathrm{k}_{\mathrm{g}}+\mathrm{k}_{\mathrm{t}}+\mathrm{k}_{\mathrm{c}}
$$

The solution of equation (1) combined with equation (2) yields:

$$
\zeta_{p}=1-e^{-k_{1} t}
$$

A wood conversion of $63 \%$ corresponds to:

$k_{1} t_{1}=1$

A typical result of the kinetic model is presented in figure 1 . 


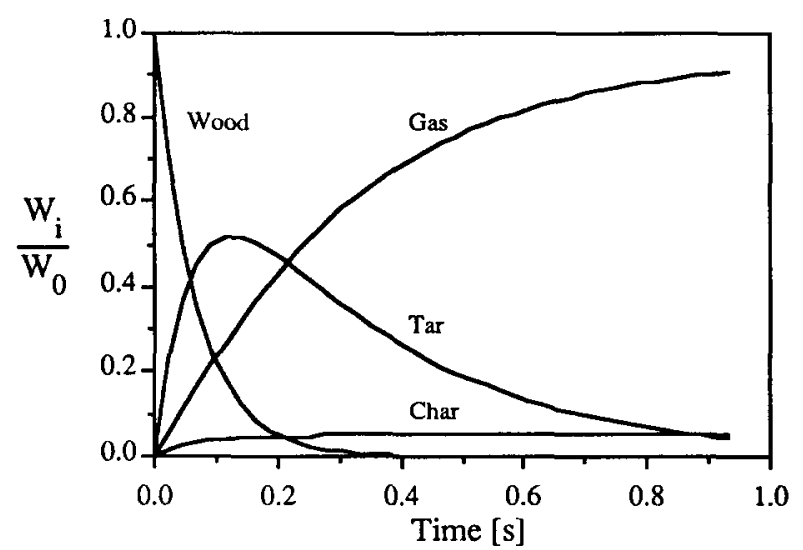

Figure 1. The weight fraction $\mathrm{W}_{\mathrm{i}} / \mathrm{W}_{0}$ of each product as a function of the time. Intermediate products remain at reactor conditions. Typical kinetic constants which have been used in this simulation are $\mathrm{k}_{\mathrm{g}}=2.2, \mathrm{k}_{\mathrm{t}}=12, \mathrm{k}_{\mathrm{c}}=0.8$ and $\mathrm{k}_{2}=3.4 \mathrm{~s}^{-1}$, evaluated at $873 \mathrm{~K}$.

\section{EQUIPMENT AND EXPERIMENTAL PROCEDURES}

Pine wood sawdust was hammer-milled and screened to particle diameters varying between 100 and $212 \mu \mathrm{m}$. This sieve fraction was used in all TGA or drop tube experiments. Micro-photographs revealed that the sawdust particles belonging to the sieve fraction of 100-212 $\mu \mathrm{m}$ had a cylindrical shape with an average diameter of $90 \mu \mathrm{m}$, and an average length of $320 \mu \mathrm{m}$. Before every experiment, the sawdust was dried for 12 hours at a temperature of $105^{\circ} \mathrm{C}$. The elemental composition of pine wood derived from analyses can be formulated as $\mathrm{C}_{12} \mathrm{H}_{20} \mathrm{O}_{9}$.

\section{Thermogravimetric analyser}

A Setaram TG 85-1000 thermogravimetric analyser has been used to measure the weight change of a decomposing wood sample as a function of time. After attaching the sample holder to the TGA, a hot tube furnace was positioned quickly around the sample. At the relatively high TGA temperature of $380^{\circ} \mathrm{C}$ it has been checked whether the rate of heat transfer to the sample holder could disturb the kinetic measurements. This was done by varying the sample weight ( 1 to $7 \mathrm{mg}$ ), the average wood particle diameter (20 to $300 \mu \mathrm{m})$ and the material of the sample holder (quartz or copper foil). Neither of these factors had an effect on the observed wood decomposition rate. Consequently it was concluded that possible heat transfer limitations could be excluded. 


\section{Drop tube reactor}

The drop tube reactor consists of a vertically positioned $20 \mathrm{~mm}$ inner diameter stainless steel tube of which the length could be varied from 0.3 to 1.2 meter. After entering the tube through a water-cooled inlet device, the sawdust was transported by nitrogen gas towards the drop tube exit. At the tube exit, the nitrogen carrier gas flow was mixed with a cold equimolar nitrogen flow to achieve a rapid thermal quench of the product gas flow. Partly converted solids were collected in a pot which was positioned below the drop tube. The chemical conversion of the sawdust was determined by the weight measurement of the solid product.

\section{Product composition measurements for ultimate tar yield conditions}

The product composition as a function of the temperature has been measured in a modified version of the drop tube reactor, (tube length of $0.25 \mathrm{~m}$ ). In the top of the drop tube a steel-wire plug was inserted which collected all reacting particles. This steel wire plug covered the tube cross sectional area completely and was positioned $0.05 \mathrm{~m}$ below the sawdust entrance. Vapours flowing through the wire plug reached the exit of the tube in less than $40 \mathrm{~ms}$ and were immediately quenched after leaving the tube. At a temperature of $600^{\circ} \mathrm{C}$, no significant degradation of the produced vapours could be measured for vapour residence times smaller then $100 \mathrm{~ms}$, and a constant tar yield was obtained under these conditions. The non-condensible fraction of the produced vapours is called "gas", while the condensible product is called "tar". For the conditions of these measurements the quantity of liquid products is maximal (ultimate tar yield).

\section{RESULTS}

Results of the product composition measurements are presented in figure 2. In most experiments, the total weight of the collected products was approximately $90 \%$ of the initial weight of wood. The deviation from a full weight recoverage is due to weight losses in the collection system.

Figure 2. The measured weight fractions of the products as a function of the pyrolysis temperature. Tar vapours and gases are thermally quenched within $40 \mathrm{~ms}$.

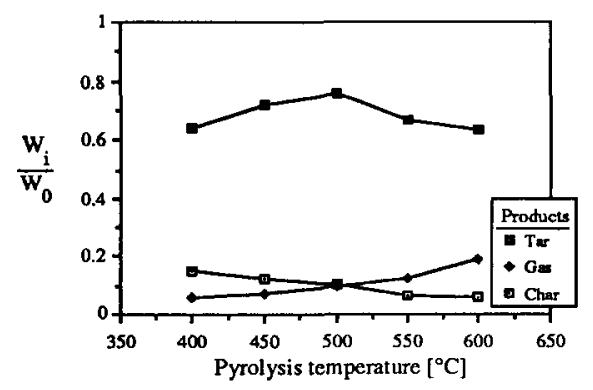


Because of the rapid removal of the pyrolysis vapours, secondary tar cracking reactions are suppressed. From the measurements presented in figure 2, the rate constants of the reaction path model can be evaluated. The formulation used in equation (5) takes an incomplete collection efficiency of the pyrolysis products into account.

$$
\frac{w_{i}}{w_{g}+w_{t}+w_{c}}=\frac{k_{i}}{k_{g}+k_{t}+k_{c}} \quad i=g, t, c .
$$

The particle conversion in the TGA and the drop tube reactor has been calculated with equation (2). Figure 3 shows direct results of typical TGA experiments at three different temperatures. Results of the drop tube experiments are presented in a similar diagram (Fig. 4), now containing discrete data points plus the corresponding best-fit lines. These lines are obtained by introducing the proper value of $k_{1}$ into equation (3).

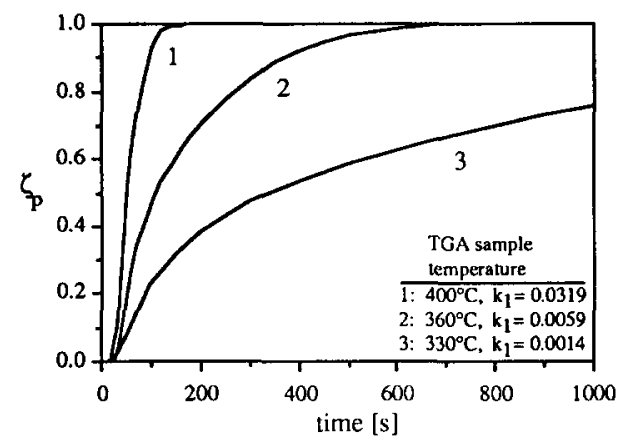

Figure 3. Mass conversion $\zeta_{p}$ of sawdust as a function of time, measured in the thermogravimetric analyser.

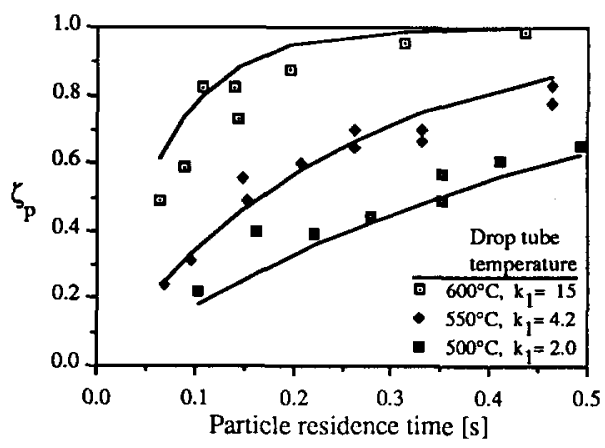

Figure 4. Measured mass conversion $\zeta_{p}$ of sawdust as a function of the residence time in the drop tube reactor.

True kinetics of the sawdust decomposition can only be measured if no thermal gradients inside the particle occur, which corresponds to a small value for the particle Biot number. In addition, external heat transfer limitations should not limit the pyrolysis process which corresponds to a large value of the pyrolysis number Py', see [3].

$$
\mathrm{Bi}=\frac{\alpha \mathrm{r}_{\mathrm{p}}}{\lambda_{\mathrm{p}}} \ll 1 \quad \text { and } \quad P y^{\prime}=\frac{\alpha}{\mathrm{k}_{1} \rho_{\mathrm{p}} \mathrm{C}_{\mathrm{p}} \mathrm{r}_{\mathrm{p}}} \gg 1
$$

During the time the reacting particle travels through the drop tube, its temperature should not deviate too much from the gas phase temperature. The 
temperature difference between a particle and the gas phase bulk can be estimated from the heat balance applied to a single particle.

$k_{1} \rho_{w} \Delta H_{r}=\alpha \frac{A_{p}}{V_{p}}\left(T_{g}-T_{p}\right)$

Calculations showed that conditions $(6,7)$ are satisfied. With respect to relation (8) it can be estimated that the error in the prediction of $\mathrm{k}_{1}$ is less than $30 \%$ if the endothermic heat of reaction $\Delta \mathrm{H}_{\mathrm{r}}$ is smaller than $500 \mathrm{KJ} / \mathrm{kg}$, a value reported in reference [4].

The first-order rate constant of the reaction path model was derived from maximizing the correlation between the experimental data and the reaction path model prediction by fitting the $k_{1}$ value. Results of this method are given in figure 5 .

Figure 5. Values of the first-order wood decomposition rate constant at different temperatures, measured in a thermogravimetric analyser and a drop tube reactor.

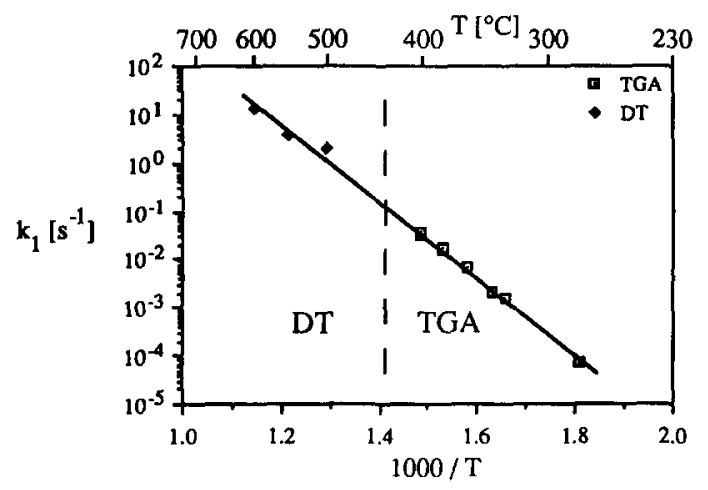

The observed temperature dependence for first-order rate constant of the wood decomposition could be described by an Arrhenius type of relation:

$k_{1}=1.410^{10} e^{-\frac{150000}{R T}}$

$573 \mathrm{~K}<\mathrm{T}<873 \mathrm{~K}$

\section{CONCLUSIONS}

Below a temperature of $400{ }^{\circ} \mathrm{C}$ the kinetics of wood decomposition can be succesfully measured in a TGA . Above $500^{\circ} \mathrm{C}$ a drop tube should be applied. From the combined results of such measurements an Arrhenius relationship between the first-order rate constant and the temperature has been established. The parameters of the Arrhenius equation (9) are: $\mathrm{k}_{0}=1.410^{10} \mathrm{~s}^{-1}$ and $\mathrm{E}_{\mathrm{a}}=$ $150 \mathrm{KJ} . \mathrm{mol}^{-1}$. From measurements of the ultimate gas, tar and char yields it is possible to evaluate the various rate constants of the reaction path model. 


\section{NOTATION}

$\begin{array}{lll}A & \text { Surface } & {\left[\mathrm{m}^{2}\right]} \\ \mathrm{Bi} & \text { Particle Biot number } & {[-]} \\ \mathbf{C} & \text { Heat capacity } & {\left[\mathrm{J} \mathrm{kg}^{-1} \mathrm{~K}^{-1}\right]} \\ \mathrm{E}_{\mathrm{a}} & \text { Reaction activation energy } & {\left[\mathrm{J} \mathrm{mol}^{-1}\right]} \\ \Delta \mathrm{H}_{\mathbf{r}} & \text { Heat of reaction } & {\left[\mathrm{J} \mathrm{kg}^{-1}\right]} \\ \mathbf{k}_{\mathbf{1}} & \text { first-order rate constant of the primary } & {\left[\mathrm{kg} \mathrm{kg}^{-1} \mathrm{~s}^{-1}\right]} \\ & \text { wood decomposition reaction } & \\ \mathbf{k}_{2} & \text { first-order rate constant of the secondary } & {\left[\mathrm{kg} \mathrm{kg}^{-1} \mathrm{~s}^{-1}\right]} \\ & \text { tar cracking reaction } & \\ \mathbf{P y} & \text { Particle pyrolysis number } & {[-]} \\ \mathbf{r} & \text { Particle radius } & {[\mathrm{m}]} \\ \mathrm{R} & \text { Universal gas constant } & {\left[\mathrm{J} \mathrm{mol}{ }^{-1} \mathrm{~K}^{-1}\right]} \\ \mathbf{t} & \text { Time } & {[\mathrm{s}]} \\ \mathbf{t}_{1} & \text { Real time required for } 63 \% \text { wood conversion } & {[\mathrm{s}]} \\ \mathrm{T} & \text { Temperature } & {[\mathrm{K}]} \\ \mathbf{V} & \text { Volume } & {\left[\mathrm{m}^{3}\right]} \\ \mathrm{W} & \text { Weight } & {[\mathrm{N}]}\end{array}$

Greek symbols

$\alpha \quad$ External heat transfer coefficient

$\lambda$ Thermal conductivity

[W m ${ }^{-2} \mathrm{~K}^{-1}$ ]

Subscripts

$\rho$ Density

[W m-1 $\mathrm{K}^{-1}$ ]

c char

$\zeta_{p} \quad$ Mass conversion of the sawdust particles

$\left[\mathrm{kg} \mathrm{m}^{-3}\right.$ ]

g gas

p particle

$[-]$

t tar

w wood

0 initial

* ultimate

\section{REFERENCES}

1. Antal, M.J. Biomass pyrolysis: a review of the literature. Part 1, carbohydrate pyrolysis. Advances in solar energy, 1, 61, (1983).

2. Shafizadeh, F. and Chin, P.P.S. Wood technology, chemical aspects. Am.Chem.Soc. Symp.Ser., 43, 57, (1977).

3. Pyle, D.L. and Zaror, C.A. Heat transfer and kinetics in the low temperature pyrolysis of solids. Chem.Eng.Sci., 39, 147, (1984).

4. Deglise, X., Richard, C., Rolin, A. and Francois, H. Fast pyrolysis of lignocellulosic materials at short residence time. 1st E.C. Conference, Applied Science Publishers Ltd, London, 1981, p 548. 


\section{Discussion}

Flash pyrolysis kinetics of pine wood

B.M. Wagenaar, W. Prins and W.P.M van Swaaij

Question: J.E. Hustad

Biomass can have different compositions of cellulose, hemi-cellulose and lignin. Your model represents a very simple description of the wood structure, visually only cellulose. Do you have plans to incorporate a more complex structure suitable for several biomass fuels?

\section{Answer}

The material used in the experimental investigations was pine-wood sawdust which displayed a first-order behaviour in weight change, in correspondence with the results from the random chain dissociation model. The model can be extended to contain other features, but this must be based on well-defined parameters. 